\title{
PERAN PIMPINAN PANTI PELAYANAN SOSIAL PENGEMIS GELANDANGAN ORANG TERLANTAR (PGOT) MARDI UTOMO DALAM UPAYA REHABILITASI DAN PEMBERDAYAAN UNTUK KEMANDIRIAN PEMERLU PELAYANAN KESEJAHTERAAN SOSIAL (PPKS)
}

\author{
Maryatun', Soni Akhmad Nulhaqim² \\ 1,2Pascasarjana Kesejahteraan Sosial, FISIP - Universitas Padjadjaran \\ maryatun1383@gmail.com, soni.nulhaqim@unpad.ac.id
}

\begin{abstract}
ABSTRAK
Administrator memiliki peran besar dalam rangka pelaksanaan tugas fungsi panti pelayanan sosial melalui upaya rehabilitasi dan pemberdayaan untuk kemandirian Pemerlu Pelayanan Kesejahteraan Sosial (PPKS). Panti Pelayanan Sosial Pengemis Gelandangan Orang Terlantar Mardi Utomo Semarang memiliki tugas pokok melaksanakan sebagian kegiatan teknis operasional ataupun penunjang Dinas Sosial Provinsi Jawa Tengah di bidang rehabilitasi sosial penyandang masalah kesejahteraan sosial khusus pengemis, gelandangan orang terlantar (PGOT). Dalam melaksanakan tugas pokok rehabilitasi, panti pelayanan sosial PGOT Mardi Utomo menselaraskannya dengan upaya pemberdayaan melalui pelaksanaan manajemen open system dengan media pengembangan Taman Edukasi Pelangi dan Agrososial Mardi Utomo. Terkait hal tersebut, penelitian ini bertujuan untuk menggambarkan peranan/tindakan kepala panti dalam upaya rehabilitasi dan pemberdayaan untuk kemandirian Pemerlu Pelayanan Kesejahteraan Sosial (PPKS). Teori yang digunakan untuk mengetahui peranan administrator dalam penelitian ini menggunakan konsep organisasi layanan manusia dilihat dari Social Work Administrator. Metode penelitian deskriptif kualitatif, teknik pengumpulan data melalui wawancara dan studi literatur. Hasil penelitian menunjukkan bahwa kepala Panti Pelayanan Sosial Pengemis Gelandangan Orang Terlantar Mardi Utomo Semarang sudah melaksanakan peran/ tindakannya dengan baik dalam upaya rehabilitasi dan pemberdayaan dilihat dari aspek penerimaan, kreatif, demokrasi, kepercayaan, perencanaan, pengorganisasian dan pembuatan keputusan yang terkait upaya rehabilitasi dan pemberdayaan sosial untuk kemandirian PPKS.
\end{abstract}

Kata kunci : Pimpinan panti, rehabilitasi dan pemberdayaan, kemandirian PPKS.

\section{ABSTRACK}

Administrators have a large role in the implementation of the functioning duties of social services through rehabilitation and empowerment efforts for the independence of social welfare service (PPKS). Social Services Orphanage Beggar Homeless People Displaced Mardi Utomo Semarang has a duty in the field of social rehabilitation with social welfare problems especially beggars, homeless people displaced. Panti Mardi Utomo aligns it with empowerment efforts through the implementation of open system management with the development media of Taman Pendidikan Pelangi and Agrosocial Mardi Utomo. This research aims to illustrate the role of nursing heads in rehabilitation and empowerment for the independence of social welfare service. To find out the role of an administrator using the human services organization concept is viewed from the Social Work Administrator. Qualitative descriptive research methods, interview data collection techniques and literature studies. The results showed the head of Social Services Forgging Homeless People Mardi Utomo Semarang has performed a good role in rehabilitation and empowerment from the aspects of acceptance, creative, democracy, trust, planning, organizing and decision making related to rehabilitation and social empowerment for PPKS independence. 


\begin{tabular}{|c|c|c|c|c|}
\hline Share: Social Work Jurnal & VOLUME: 10 & NOMOR: 2 & HALAMAN: $143-149$ & $\begin{array}{c}\text { ISSN: 2339-0042 (p) } \\
\text { ISSN: 2528-1577 (e) } \\
\text { DOI: 10.24198/share.v10i2.30639 }\end{array}$ \\
\hline
\end{tabular}

Keywords : Leadership of institution, rehabilitation and empowerment, independence of PPKS.

\section{PENDAHULUAN}

Kajian mengenai peran pimpinan dalam organisasi layanan manusia khususnya pada panti pelayanan sosial terkait peran pimpinan dalam rangka pemberdayaan dan kemandirian Pemerlu Pelayanan Kesejahteraa Sosial (PPKS) dengan menggunakan pendekatan Social Work Administrator perlu dilakukan, mengingat organisasi layanan manusia memiliki perbedaan dengan organisasi lainnya dilihat dari aspek tujuan, teknologi dan dukungan (Jones and May). Proses penyelenggaraan organisasi layanan manusia berbeda dengan organisasi pada umumnya, tentu berkaitan dengan pekerjaan sosial sehingga tindakan yang dilakukan pimpinan organisasi layanan manusia seharusnya ada kesesuaian dengan pekerjaan sosial. Skidmore (1995) menguraikan bahwa dalam satu organisasi layanan manusia tentu tidak terlepas dari manajemen, kepemimpinan, pengambilan keputusan, hubungan antar manusia, komunikasi dan adanya satu persepsi.

Dalam implementasinya, seorang administrator yang kompeten dapat membuat badan layanan sosial efektif dan efisien. Administrator yang cakap dapat menghasilkan hasil yang diinginkan, dan pemimpin yang tidak kompeten dapat memblokir layanan dan menggagalkan staf. (Skidmore, 1995:1). Peran pimpinan organisasi layanan manusia juga ditentukan dalam tindakan mencapai keberhasilan dan tujuan organisasi.

Salah satu organisasi layanan manusia yang ada di masyarakat adalah panti pelayanan sosial, baik yang dikelola oleh swasta maupun pemerintah. Panti pelayanan sosial di bawah Dinas Sosial Provinsi Jawa Tengah yang memiliki tugas pokok bidang rehabilitasi sosial penyandang masalah kesejahteraan sosial khusus pengemis, gelandangan dan orang terlantar adalah Panti Pelayanan Sosial Pengemis Gelandangan Orang Terlantar (PGOT) Mardi Utomo Semarang. Namun, selain pelayanan rehabilitasi ada upaya pemberdayaan sosial untuk kemandirian PPKS. Berkaitan dengan hal tesebut, maka rumusan masalah yang diangkat adalah : Bagaimana seorang kepala Panti Pelayanan Sosial Pengemis Gelandangan Orang Terlantar (PGOT) Mardi Utomo Semarang melakukan tindakan dalam pelayanan rehabilitasi dan pemberdayaan sosial untuk kemandirian PPKS. Dan tujuan penelitian ini adalah mengetahui sejauh mana tindakan seorang kepala panti pelayanan sosial yang didasarkan pada aspek Social Work Administration dan memberikan saran masukan kepada Dinas Sosial Provinsi Jawa Tengah terkait tindakan seorang kepala panti yang didasarkan pada aspek Social Work Administration.

\section{METODE}

Jenis dan rancangan pada penelitian ini menggunakan metode deskriptif kualitatif. Penelitian kualitatif adalah penelitian yang menggunakan kata-kata untuk menceritakan fenomena atau gejala (Creswell, 2009). Metode penelitian dalam kajian yaitu untuk menggambarkan peran/tindakan pimpinan pada Panti Pelayanan Sosial PGOT "Mardi Utomo" Semarang dalam upaya rehabilitasi dan pemberdayaan sosial untuk kemandirian penerima manfaat/ PPKS melalui kegiatan pengembangan Taman Edukasi Pelangi dan Agrososial Mardi Utomo. Teknik pengumpulan data dalam penelitian ini melalui wawancara dengan informan dan studi literatur.

\section{HASIL DAN PEMBAHASAN}

\section{Profil Panti Pelayanan Sosial PGOT Mardi Utomo.}

Dalam Peraturan Gubernur Jawa Tengah No 31 Tahun 2018 Tentang Organisasi Dan Tata Kerja Unit Pelaksana Teknis Dinas Sosial Provinsi Jawa Tengah, diuraikan bahwa Dinas Sosial Provinsi Jawa Tengah memiliki 27 Unit Pelaksana Teknis (UPT) yang tersebar diseluruh wilayah Jawa Tengah. Panti Pelayanan Sosial PGOT Mardi Utomo Semarang merupakan salah satu UPT yang memiliki fungsi: a. penyusunan rencana teknis operasional di bidang penyantunan dan rujukan serta bimbingan dan rehabilitasi sosial; b. koordinasi dan pelaksanaan kebijakan teknis operasional di bidang penyantunan dan rujukan serta bimbingan dan rehabilitasi sosial; $c$. evaluasi, dan pelaporan bidang penyantunan dan rujukan serta bimbingan dan rehabilitasi sosial; $d$. pengelolaan ketatausahaan; dan e. pelaksanaan tugas kedinasan lain yang diberikan oleh Kepala Dinas sesuai dengan tugas dan fungsinya.

Tugas dimaksud meliputi: a. menyiapkan penyusunan rencana teknis operasional di bidang bimbingan dan rehabilitasi sosial; b. menyiapkan pengoordinasian pelaksanaan teknis operasional 


\begin{tabular}{|c|c|c|c|c|}
\hline Share: Social Work Jurnal & VOLUME: 10 & NOMOR: 2 & HALAMAN: 143 - 149 & $\begin{array}{c}\text { ISSN: } 2339-0042(p) \\
\text { ISSN: } 2528-1577(e) \\
\text { DOI: } 10.24198 / \text { share.v10i2.30639 }\end{array}$ \\
\hline
\end{tabular}

di bidang bimbingan dan rehabilitasi sosial; c. menyiapkan pelaksanaan pengungkapan dan pemahaman masalah kepada penerima manfaat; d. menyiapkan pelaksanaan penyusunan rencana pemecahan masalah kepada penerima manfaat; e. menyiapkan pelaksanaan bimbingan fisik, bimbingan mental psikososial, bimbingan mental spiritual, bimbingan sosial, bimbingan keterampilan dan bimbingan peningkatan kemampuan lainnya kepada penerima manfaat; $f$. menyiapkan pelaksanaan resosialisasi kepada penerima manfaat; g. menyiapkan pelaksanaan penyaluran dan terminasi kepada penerima manfaat; h. menyiapkan pelaksanaan bimbingan lanjut kepada penerima manfaat; i. menyiapkan evaluasi dan pelaporan di bidang bimbingan dan rehabilitasi sosial; dan j. melakukan tugas kedinasan lain yang diberikan oleh pimpinan.

Kepala Panti yang berkedudukan di bawah dan bertanggung jawab kepada Kepala Dinas Sosial Provinsi Jawa Tengah yang memiliki tugas pokok melaksanakan sebagian kegiatan teknis operasional atau sebagian penunjang Dinas Sosial Provinsi Jawa Tengah di bidang rehabilitasi sosial penyandang masalah kesejahteraan sosial khusus pengemis, gelandangan dan orang terlantar. Rehabilitasi sosial sendiri merupakan proses refungsionalisasi dan pengembangan untuk memungkinkan seseorang mampu melaksanakan fungsi sosialnya secara wajar dalam kehidupan masyarakat. Panti Pelayanan Sosial Mardi Utomo Semarang, menselaraskannya melalui usaha pemberdayaan untuk Pemerlu Pelayanan Kesejahteraan Sosial (PPKS) dengan penguatan system kelembagaan membuat program "Taman Edukasi Pelangi dan Agrososial Mardi Utomo" sebagai pendukung penyelenggaraan pelayanan kesejahteraan sosial.

\section{Peran Administrator dalam Upaya Rehabilitasi dan Pemberdayaan.}

\section{a. Rehabilitasi dan Pemberdayaan Sosial}

Sebagaimana terdapat dalam UndangUndang Kesejahteraan Sosial, bentuk pelaksanaan rehabilitasi sosial yaitu dimaksudkan untuk memulihkan dan mengembangkan kemampuan seseorang yang mengalami disfungsi sosial agar dapat melaksanakan fungsi sosialnya secara wajar. Rehabilitasi Sosial dapat dilaksanakan secara persuasif, motivatif, koersif, baik dalam keluarga, masyarakat maupun panti sosial: a. motivasi dan diagnosis psikososial; b. perawatan dan pengasuhan; c. pelatihan vokasional dan pembinaan kewirausahaan; d. bimbingan mental spiritual; e. bimbingan fisik; f. bimbingan sosial dan konseling psikososial; g. pelayanan aksesibilitas; h. bantuan dan asistensi sosial; i. bimbingan resosialisasi; j. bimbingan lanjut; dan/atau k. rujukan.

Dalam Peraturan Menteri Sosial No. 16 Tahun 2019 tentang Standar Nasional Rehabilitasi Sosial dikatakan bahwa Rehabilitasi Sosial adalah proses refungsionalisasi dan pengembangan untuk memungkinkan seseorang mampu melaksanakan fungsi sosialnya secara wajar dalam kehidupan masyarakat. Rehabilitasi Sosial dimaksudkan untuk memulihkan dan mengembangkan kemampuan PPKS, keluarga, dan masyarakat yang mengalami disfungsi sosial agar dapat melaksanakan fungsi sosialnya secara wajar. Rehabilitasi Sosial dilaksanakan dengan tahapan: a. pendekatan awal; b. asesmen; c. penyusunan rencana intervensi; d. intervensi; e. resosialisasi; f. terminasi; dan g. bimbingan lanjut.

Rehabilitasi Sosial bagi Gelandangan dan Pengemis di dalam Panti Sosial diberikan kepada PPKS memiliki kriteria: a. kepala keluarga berusia 19 (sembilan belas) tahun sampai dengan 60 (enam puluh) tahun; b. tidak terpenuhi kebutuhan dasarnya, tidak terpelihara, tidak terawat, dan tidak terurus; c. tidak memiliki tempat tinggal tetap; dan d. tidak ada lagi perseorangan, keluarga, dan/atau masyarakat yang peduli. Dalam melaksanakan rehabilitasi terhadap pemerlu pelayanan kesejahteraan sosial yang menjadi tugas pokok, Panti Pelayanan Sosial PGOT Mardi Utomo melakukan penyelarasan dengan upaya pemberdayaan sosial bagi PPKS. Pengertian pemberdayaan dalam Peraturan Pemerintah RI No. 39 Tahun 2012 adalah semua upaya yang diarahkan untuk menjadikan warga negara yang mengalami masalah sosial mempunyai daya, sehingga mampu memenuhi kebutuhan dasarnya. Pemberdayaan sosial dimaksudkan untuk memberdayakan seseorang, keluarga, kelompok, dan masyarakat yang mengalami masalah kesejahteraan sosial agar mampu memenuhi kebutuhannya secara mandiri dan meningkatkan peran serta lembaga dan/atau perseorangan sebagai potensi dan sumber daya dalam penyelenggaraan kesejahteraan sosial.

Pemberdayaan sosial sebagaimana dimaksud dilakukan melalui peningkatan kemauan an kemampuan; penggalian potensi dan sumber daya; penggalian nilai-nilai dasar; pemberian akses; dan/atau pemberian bantuan usaha. Berkaitan dengan pemberdayaan tersebut, Panti Pelayanan Sosial PGOT Mardi Utomo memlakukan upaya pemberdayaan kepada pemerlu pelayanan kesejahteraan sosial diantaranya : a. upaya peningkatan kemauan dan kemampuan dalam hal pemberian ketrampilan seperti pertukangan, 


\begin{tabular}{|c|c|c|c|c|}
\hline Share: Social Work Jurnal & VOLUME: 10 & NOMOR: 2 & HALAMAN: 143 - 149 & $\begin{array}{c}\text { ISSN: } 2339-0042(p) \\
\text { ISSN: } 2528-1577(e) \\
\text { DOI: } 10.24198 / \text { share.v10i2.30639 }\end{array}$ \\
\hline
\end{tabular}

penjahitan, pertanian dan berwirausaha, $b$. Penggalian potensi dan sumber daya dengan mengelola, mengembangkan Taman Pelangi/ Agrososial Mardi Utomo, c. Penggalian nilai-nilai dasar dengan memberikan PPKS pada kegiatan penyuluhan terkait pemberdayaan, d. Pemberian akses kepada PPKS yang memiliki kemauan dan kemampuan untuk mencoba berwirausaha dalam memanfaatkan keberadaan Taman Pelangi.

Lebih lanjut diuraikan mengenai tujuan pelaksanaan manajemen open system dalam pengelolaan dan pengembangan media Taman Edukasi Pelangi dan Agrososial Mardi Utomo diharapkan dapat : $1 . \quad$ Menumbuhkan keberfungsian sosial pada penerima manfaat, 2. Memotivasi penerima manfaat agar lebih inovatif dalam berkarya dan mandiri, 3. Sebagai wujud sinergi antara pihak swasta, masyarakat dan pemerintah dalam rangka penyelenggaraan kesejahteraan sosial. 4. Meningkatkan semangat penerima manfaat untuk menjadi lebih baik dan berdaya guna sebelum mereka kembali ke lingkungan masyarakat.

\section{b. Tindakan Kepala Panti dalam administrasi pekerjaan sosial.}

Sebagaimana telah diuraikan sebelumnya bahwa Panti Pelayanan Sosial PGOT Mardi Utomo melibatkan PPKS dalam pengelolaan dan pengembangan Taman Edukasi Pelangi dan Agrososial Mardi Utomo sebagai bentuk pemberdayaan bagi PPKS. Merriam webster dan oxford english dictionary dalam (Riskasetyoning, 2017) menyampaikan bahwa empowerment mengandung dua pengertian, pertama to give power or authority to, dan kedua to give ability to or enable. Pengertian pertama diartikan sebagai memberi kekuasaan, mengalihkan kekuatan atau mendelegasikan otoritas ke pihak lain dan pengertian kedua sebagai upaya memberikan kemampuan atau keberdayaan.

Dari pengertian tersebut, akan sangat menentukan peran yang dilakukan oleh pimpinan panti dalam upaya pemberdayaan yang dilakukan melalui program "Taman Edukasi dan Agrososial Pelangi". Menurut (Skidmore, 1995), dalam melaksanakan administrasi pekerjaan sosial, tindakan administrator dalam Organisasi Layanan Manusia dapat dikategorikan sebagai berikut : a. penerimaan (accepting) perhatian (caring), b. kreatif (creating), c. demokrasi (democrating), d. kepercayaan (trusting), e.menyetujui (approving), f. mempertahankan keseimbangan diri (balancing), g. perencanaan (planning), h. pengorganisasian (organizing), i. menentukan prioritas (setting priorities), j. pendelegasian (delegating), k. berinteraksi (interacting) berinteraksi dengan masyarakat dan profesi pemberi bantuan lain, I. pembuatan keputusan (decession making), m. memfasilitasi (facilitting), n. komunikasi (communicating), o. memanfaatkan waktu (timing) ide, p. membangun (building), q. memotivasi (motivating). Dalam penelitian ini, mengaitkan adanya hubungan erat dari tindakan yang ditujukkan seorang pimpinan panti pelayanan sosial PGOT Mardi Utomo dalam melaksanakan program pemberdayaan untuk kemandirian Pemerlu Pelayanan Kesejahteraan Sosial. Dapat dikatakan bahwa pimpinan panti sudah melaksanakan keseluruhan tindakan administrasi pekerjaan sosial tersebut, namun demikian penulis membatasi tindakan yang sangat mempengaruhi pelaksanaan program pemberdayaan pada Panti Pelayanan Sosial PGOT Mardi Utomo diantaranya yaitu :

a. Penerimaan (accepting)

Nilai praktek pekerjaan sosial yang utama adalah penerimaan, yang artinya menerima klien memperlakukan mereka secara manusiawi dan secara baik serta memberikan mereka martabat dan harga diri (Biestek, 1957, dalam DuBois \& Miley, 2005:126). Dalam aspek penerimaan pimpinan panti mengungkapkannya melalui kepedulian yang nyata, mendengarkan dengan baik, menghormati sudut pandang orang lain, dan menciptakan iklim saling menghormati. Pimpinan panti juga menganjurkan pengembangan klien berdasarkan kekuatan klien dan mengakui potensi yang mereka miliki masing-masing untuk berubah.

b. Kreatif (creating)

Seorang administrator pekerjaan sosial harus kreatif, pribadi yang gemar untuk merintis atau menetapkan kebijakan yang inovatif, metode dan prosedur yang akan meningkatkan jasa dan hubungan staf (Ramadhani, Widya S, 2016). Sosok pimpinan yang kreatif dimiliki oleh kepala Panti Pelayanan Sosial Mardi Utomo Semarang, dalam memproyeksikan kegiatan manajemen open sistem untuk pengembangan Taman Edukasi dan Agrosial Mardi Utomo Semarang melalui kerjasama dengan berbagai perusahaan swasta dan perguruan tinggi di Jawa Tengah, antara lain dengan PT. PHAPROS Tbk melalui program bantuan obat-obatan ringan, bibit pohon rambutan dan pohon durian, Politeknik Negeri Semarang melalui kegiatan Entepreneur training centre/ pelatihan kewirausahaan.

c. Demokrasi (democrating)

Diuraikan oleh (Mardiana, 2014) bahwa mengukur gaya kepemimpinan terhadap kinerja karyawan menunjukkan ada hubungan positif 


\begin{tabular}{|c|c|c|c|c|}
\hline Share: Social Work Jurnal & VOLUME: 10 & NOMOR: 2 & HALAMAN: 143 - 149 & $\begin{array}{c}\text { ISSN: } 2339-0042(p) \\
\text { ISSN: } 2528-1577(e) \\
\text { DOI: } 10.24198 / \text { share.v10i2.30639 }\end{array}$ \\
\hline
\end{tabular}

signifikan, oleh karena itu gaya kepemimpinan yang demokratis harus dipertahankan agar kinerja pegawai dapat dipertahan bahkan ditingkatkan. Bentuk kepemimpinan ini menempatkan manusia sebagai faktor utama dan terpenting. Setiap orang akan dihargai dan dihormati sebagai manusia yang memiliki kemampuan, kemauan, pikiran, minat, perhatian dan pendapat yang berbeda antar satu dengan yang lainnya, setiap orang harus dimanfaatkan dengan mengikutsertakannya dalam kegiatan organisasi. Keikutsertaan itu disesuaikan dengan posisinya, wewenang yang memiliki dan tanggung jawab bagi tercapaianya tujuan bersama.

Pimpinan pada Panti Pelayanan Sosial Mardi Utomo Semarang, dalam melaksanakan tugas manajerialnya senantiasa memberikan kebebasan bagi unsur yang berada di bawahnya dalam menyampaikan pendapat, memberikan kesempatan melakukan inovasi dan kreatifitasnya. Dalam suasana kerja kepemimpinan yang demokratis sebagian besar atau hampir seluruh kebijakan dan keputusan-keputusan penting berasal dan disesuaikan dengan tuntutan-tuntutan situasi kelompok, dimana pemimpin bersamasama dengan anggota kelompok ambil bagian secara aktif di dalam perumusan kebijakan umum, keputusan-keputusan penting dan program lembaga kerja itu termasuk memberikan kesempatan bagi PPKS untuk menyampaikan pendapat dan masukan dalam melaksanakan program pengembangan Taman Edukasi Pelangi dan Agrososial Mardi Utomo. Meskipun tetap ada wewenang bagi pimpinan panti untuk memberikan keputusan yang dipandang perlu kebijakan dari pimpinan langsung.

d. Kepercayaan (trusting)

Pimpinan harus mempunyai kepercayaan yang implisit kepada stafnya (Ramadhani, Widya $S$, 2016). Dengan mengamati pelaksanaan program pemberdayaan melalui taman edukasi pelangi dan agrososial Mardi Utomo Semarang, pimpinan panti terlihat memberikan kepercayaan kepada semua bagian yang terlibat di dalamnya. Memberikan kepercayaan dalam mengelola keuangan, bagaimana proses pengembangan yang dilakukan hingga perluasan jaringan, tentu pimpinan panti tetap memonitor dan mengevaluasi setiap hasil pekerjaan yang dilaksanakan.

e. Perencanaan (Planning)

Perencanaan merupakan susunan langkahlangkah secara sistematik dan teratur untuk mencapai tujuan organisasi atau memecahkan masalah tertentu. Perencanaan juga diartikan sebagai upaya memanfaatkan sumber-sumber yang tersedia dengan memperhatikan segala keterbatasan guna mencapai tujuan secara efisien dan efektif. Perencanaan merupakan langkah awal dalam proses manajemen, dengan merencanakan aktivitas organisasi kedepan, segala sumber daya dalam organisasi difokuskan pada pencapaian tujuan organisasi, yang harus dilakukan yaitu melakukan prakiraan (rencana) kegiatan organisasi yang berfungsi untuk menentukan rencana kegiatan yang akan dilaksanakan kedepan oleh organisasi sebagai upaya mencapai tujuan organisasi. Rencana harus memperhatikan tujuan organisasi, sumber daya organisasi dan juga melakukan suatu analisis organisasi (bisa menggunakan SWOT) untuk mengetahui potensi internal dan eksternal termasuk penyesuaian kebutuhan penganggaran. Ini sudah dilaksanakan oleh pimpinan panti selaku kuasa pengguna anggaran, yang tentunya paham akan kondisi keuangan yang dimiliki sangatlah terbatas, sehingga selain tetap membuat usulan anggaran untuk pengembangan Taman Edukasi Pelangi dan Agrososial Mardi Utomo juga melakukan upaya fundrising kepada perusahaan maupun instansi yang dipandang memiliki kesamaan visi misi.

\section{f. Pengorganisasian (Organizing)}

Pengorganisasian diartikan sebagai kegiatan pembagian tugas-tugas pada orang yang terlibat dalam aktivitas organisasi, sesuai dengan kompetensi SDM yang dimiliki. Dengan demikian dapat dikatakan bahwa kegiatan ini merupakan keseluruhan proses memilih orang-orang serta mengalokasikannya sarana dan prasarana untuk menunjang tugas orang-orang itu dalam organisasi, serta mengatur mekanisme kerjanya sehingga dapat menjamin pencapaian tujuan program dan tujuan organisasi. Menurut George R. Terry, dalam Indartono, Setyabudi (2014) tugas pengorganisasian adalah mengharmonisasikan kelompok orang yang berbeda, mempertemukan macam-macam kepentingan dan memanfaatkan seluruh kemampuan kesuatu arah tertentu. Dalam hal pengorganisasian, kepala panti sudah melakukan staffing (penempatan staf) dan pemaduan segala sumber daya organisasi termasuk menyusun analisis beban kerja pegawai agar dalam melaksanakan tugas fungsi panti tidak terkendala. Staffing sangat penting dalam pengorganisasian, kepala panti telah menempatkan orang yang tepat pada bagian yang sesuai (the right man in the right place), sehingga kelangsungan aktivitas organisasi dapat terlaksana dengan baik. Upaya peningkatan SDM panti sudah dilaksanakan dengan membuat usulan Analisis Beban Kerja 


\begin{tabular}{|c|c|c|c|c|}
\hline Share: Social Work Jurnal & VOLUME: 10 & NOMOR: 2 & HALAMAN: 143 - 149 & $\begin{array}{c}\text { ISSN: } 2339-0042(p) \\
\text { ISSN: } 2528-1577(e) \\
\text { DOI: } 10.24198 / \text { share.v10i2.30639 }\end{array}$ \\
\hline
\end{tabular}

Pegawai, dengan melihat jumlah PPKS 110 (seratus sepuluh) orang, staf 18 (delapan belas) dan 2 (fungsional Peksos).

g. Pendelegasian (delegating)

Seorang pimpinan organisasi sebagai manusia mempunyai waktu, kemampuan dan perhatian yang sangat terbatas maka tidaklah mungkin seorang pimpinan itu dapat melaksanakan tugasnya sendiri, sungguhpun pimpinan itu harus bertanggung jawab akan pelaksanaan tugasnya dengan sebaik mungkin. Berkaitan dengan itu, seorang manajer perlu mendelegasikan sebagian tugas kepada bawahannya. Pendelagasian wewenang adalah suatu pelimpahan hak atau kekuasaan pimpinan terhadap bawahannya untuk melaksanakan tugastugasnya dengan sekaligus meminta pertanggung jawaban atas penyelesaian tugas-tugas tersebut. Menurut (James, A.F.Stoner, 1996) jika seorang manajer mendelegasikan tugasnya kepada bawahan maka ia harus mendelegasikan kekuasaannya yang artinya jika seorang diserahi tugas untuk melakanakan suatu tugas tertentu, ia mbertanggungjawab dalam melaksanakan tugas tersebut. Hal ini dilakukan oleh pimpinan panti dalam penyelenggaraan Taman Edukasi Pelangi dan Agrososial dengan menugaskan Kepala Sub Bagian Tata Usaha untuk bertindak sebagai ketua, diantaranya mempertimbangkan aspek pengalaman pemberdayaan sebelumnya saat masih bertugas pada bidang Pemberdayaan Sosial.

h. Pembuatan keputusan (decession making)

Defenisi-defenisi Pengambilan Keputusan

Menurut Beberapa Ahli dalam Indartono Setyabudi (2014) diantaranya adalah: Pengambilan keputusan dapat didefinisikan sebagai pemilihan alternatif kelakuan tertentu dari dua atau lebih alternatif yang ada. G. R. Terry sedang menurut Harold Koontz dan Cyril ODonnel. Pengambilan keputusan adalah pemilihan diantara alternatif-alternatif mengenai sesuatu cara bertindak adalah inti dari perencanaan. Suatu rencana dapat dikatakan tidak ada, jika tidak ada keputusan suatu sumber yang dapat dipercaya, petunjuk atau reputasi yang telah dibuat. Hal ini seperti yang sudah diuraikan pada tindakan demokrasi yang dilakukan pimpinan panti. Meskipun pimpinan panti bersifat demokratis, tetapi juga memiliki kewenangan dalam memberikan keputusan yang tepat untuk kepentingan Panti Pelayanan Sosial Pengemis Gelandangan Orang Terlantar Mardi Utomo Semarang. Keputusan menjadi cara bertindak dari pimpinan sebagai upaya pencapaian sasaran dan pemecahan masalah.

\section{Kemandirian Pemerlu Pelayanan Kesejahteraan Sosial (PPKS) \\ Kemandirian (self reliance) berkenaan} dengan tugas dan ketrampilan bagaimana mengerjakan sesuatu, mencapai sesuatu dan bagaimana mengelola sesuatu (Parker, 2005:226). Dari pengertian tersebut dapat dilihat salah satu permasalahan yang dimiliki oleh Gepeng, bahwa mereka belum dapat melaksanakan tugas, tidak memiliki ketrampilan dan mengalami kesulitan dalam mengelola segala sesuatu yang berkaitan dengan kehidupan dan pemenuhan kebutuhan. Dalam peraturan pemerintah RI No. 31 Tahun 1980 tentang Penanggulangan Gelandangan dan Pengemis, menyebutkan karakteristik yang dimiliki Gepeng yaitu : (1.) Tidak memiliki tempat tinggal, kebanyakan dari gepeng dan pengemis tidak memiliki tempat hunian atau tempat tinggal mereka ini biasa mengembara di tempat umum. (2.) Hidup di bawah garis kemiskinan, mereka tidak memiliki pengahasilan tetap yang bisa menjamin untuk kehidupan (3.) Hidup dengan penuh ketidak pastian, mereka hidup mengelandang dan mengemis. (4.) umumnya mereka memakai baju yang compang camping. Sedangkan salah satu faktor penyebab Gepeng adalah karena tidak memiliki daya untuk melakukan pekerjaan disebabkan cacat fisik, tidak berpendidikan, tidak punya rumah tetap (Putri Nurlailasari, 2015). Dengan demikian upaya rehabilitasi dan pemberdayaan yang dilakukan oleh panti pelayanan sosial PGOT Mardi Utomo dengan melibatkan PPKS dalam mengelola taman edukasi pelangi dan agrosial Mardi Utomo bisa membantu kemandirian PPKS dengan belajar berwirausaha dengan berjualan di lokasi taman, belajar tentang manajemen keuangan/ pengelolaan lahan parkir dan tiket pengunjung, belajar bercocok dan proses pembelajaran lainnya tentang nilai-nilai pemberdayaan. Mereka akan dituntun untuk memiliki ketrampilan yang menunjang pemenuhan kebutuhan hidup, mereka tidak mengandalkan belas kasihan orang lain sehingga dapat hidup normal dalam masyarakat.

\section{KESIMPULAN DAN SARAN}

\section{Kesimpulan}

Dalam melaksanakan Tugas Pokok pada Panti Pelayanan Sosial di bidang rehabilitasi sosial penyandang masalah kesejahteraan sosial Pengemis, Gelandangan, dan Orang Terlantar. Administrator mampu berperan baik dalam aspek penerimaan, kreatif, demokrasi, kepercayaan, 


\begin{tabular}{|c|c|c|c|c|}
\hline Share: Social Work Jurnal & VOLUME: 10 & NOMOR: 2 & HALAMAN: $143-149$ & $\begin{array}{c}\text { ISSN: 2339-0042 (p) } \\
\text { ISSN: 2528-1577 }(e) \\
\text { DOI: 10.24198/share.v10i2.30639 }\end{array}$ \\
\hline
\end{tabular}

perencanaan pengorganisasian, pendelegasian dan pembuatan keputusan dan meningkatkan kualitas program pelayanan rehabilitasi sosial dengan menselaraskannya melalui upaya pemberdayaan sehingga program bisa berjalan lebih dinamis dan dapat membantu upaya kemandirian PPKS PGOT dengan praktek serta pengelolaan usaha secara langsung (pelatihan kewirausahaan).

\section{Saran}

Berdasarkan Peraturan Pemerintah RI No. 39 Tahun 2012 tentang Penyelenggaraan Kesejahteraan Sosial, dan Peraturan Pemerintah RI Nomor 16 tahun 2019 tentang Standar Nasional Rehabilitasi Sosial, maka upaya peningkatan kualitas pelayanan rehabilitasi sosial melalui pemberdayaan untuk kemandirian PPKS pada Panti Pelayanan Sosial PGOT Mardi Utomo masih dapat ditingkatkan, dan saran yang disampaikan kepada Dinas Sosial Provinsi Jawa Tengah sebagai institusi yang membawahi yaitu, bahwa besarnya tanggungjawab Panti mengentaskan permasalahan Gepeng yang kompleks akan membutuhkan Sumber Daya Manusia yang memadai, jika menghitung prosentase perbandingan antara pekerja sosial sejumlah 2 (dua) orang sedangkan PPKS yang ditangani sejumlah 110 (seratus sepuluh) orang, maka secara Analisis Beban Kerja (ABK) masih membutuhkan penambahan pekerja sosial. Bahwa dengan kondisi lahan yang luas, Panti memiliki potensi besar dalam upaya Rehabilitasi dan pemberdayaan melalui manajemen open system dengan media pengembangan Taman Pelangi dan Agrososial Mardi Utomo, maka dirasa perlu mendapatkan dukungan dalam segi penganggaran guna memaksimalkan program agar dapat mencapai tujuan keberfungsian sosial PPKS.

\section{DAFTAR PUSTAKA}

Biestek, 1957, dalam DuBois \& Miley, 2005:126. (tanpa judul) Melalui $<$ https://duniakumu.com/prinsip-prinsipetik-pekerjaan-sosial/>

Creswell, Jhon W. 2009. Research Design: Qualitative, Quantitative, and Mixed Methods Approaches. SAGE Publication, United States of America, p. 296, 2009.

Mardiana 2014. Pengaruh Gaya Kepemimpinan Demokratis Terhadap Kinerja Pegawai Pada Kantor Sekretariat Daerah Kota Samarinda. Ilmu Pemerintahan, 2(1): 1802-1816.

Skidmore, Rex A. 1995. Social Work
Administration : Dinamic Management and Human Relationship

Parker, 2005: 226. (tanpa judul). Melalui http://etheses.uinmalang.ac.id/1250/6/11410126 Bab 2.pdf[ $10 / 1 / 20]$

Putri Nurlailasari, 2015 https://putrinurlaelasari.blogspot.com/2015 L12/pengertian-pengemis-dan-faktorfaktor.html

Ramadhani, Widya.S, 2016. Administrasi Pekerjaan Sosial. Universitas Padjadjaran. Melalui

https://www.academia.edu/26052982/Admi nistrasi Pekerjaan Sosial[10/6/20]

Setyabudi Indartono, Ph.D, 2014, Bab 6 Manajer Sebagai Pembuat Keputusan. Melalui https://arwana007.files.wordpress.com/201 4/09/vi-pengamen-karakter-

2014.pdf\#: : text=Pembuatan\%20keputus an\%20adalah\%20\%20serangkaian $\% 20 \% 2$ 0kegiatan $\% 20$,keputusan $\% 20$ mengenai $\% 2$ Otujuan\%20dan\%20tindakan\%20yang\%20 akan\%20dilakukan. [10/05/20]

Stoner, James, A.F. 1996. (tanpa judul). Melalui $<$ https://tulisanterkini.com/artikel/artikelilmiah/8216-pengertian-pendelegasianwewenang-dan-tangungjawab.html $>[10 / 05 / 20]$

Jones, Andrew \& May, John. Working In Human Service Organization.

Trisbiantara, Irene \& Meliala, Andreasta. 2018. Peran Leadership dalam keberhasilan implementasi Lean Management di Rumah Sakit Pelni. Jurnal Kebijakan Kesehatan Indonesia :

\section{Sumber Lainnya :}

Peraturan Gubernur Jawa Tengah Nomor 31 Tahun 2018. Tentang Organisasi Dan Tata Kerja Unit Pelaksana Teknis Dinas Sosial Provinsi Jawa Tengah

Peraturan Pemerintah RI No. 31 Tahun 1980 tentang Penanggulangan Gelandangan dan Pengemis

Peraturan Pemerintah RI No. 39 Tahun 2012 tentang penyelenggaraan Kesejahteraan Sosial 